\title{
Research Paper: Serum and Saliva Myelin Basic Protein as Multiple Sclerosis Biomarker
}

\author{
Mohammad Hossein Mirzaii-Dizgah $^{1}$ (D), Mohammad Reza Mirzaii-Dizgah ${ }^{2}$, Iraj Mirzaii-Dizgah ${ }^{3 *}$ (i) \\ 1. Student Research Committee, School of Dentistry, AJA University of Medical Sciences, Tehran, Iran. \\ 2. Student Research Committee, School of Medicine, Iran University of Medical Sciences, Tehran, Iran. \\ 3. Department of Physiology, School of Medicine, AJA University of Medical Sciences, Tehran, Iran.
}

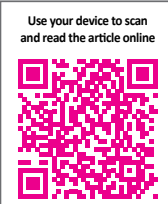

drtation: Mirzaii-Dizgah, M. H., Mirzaii-Dizgah, M. R., \& Mirzaii-Dizgah, I. (2021). Serum and Saliva Myelin Basic Protein as Multiple Sclerosis Biomarker. Basic and Clinical Neuroscience, 12(3), 309-314. http://dx.doi.org/10.32598/bcn.2021.950.2

http://dx.doi.org/10.32598/bcn.2021.950.2

\section{(i) (8)}

Article info:

Received: 03 Aug 2019

First Revision: 09 Sep 2019

Accepted: 23 Nov 2020

Available Online: 01 May 2021

Keywords:

Multiple sclerosis, Myelin

Basic Protein, Saliva, Serum

\begin{abstract}
A B S T RA C T
Introduction: Multiple Sclerosis (MS) is presented with motor and sensory function loss. It is caused by demyelination and following axonal lesion. As Myelin Basic Protein (MBP) is one of the key elements of the myelin cover, we examined the level of MBP in serum, stimulated, and unstimulated saliva as a suitable biomarker for detecting MS.

Methods: A case-control study was performed in 29 healthy women and 32 definitive relapsing-remitting MS patients hospitalized in Imam Reza hospital, Tehran, Iran. MBP level was assayed in serum and stimulated and unstimulated whole saliva.

Results: MBP was expressed at a lower level in serum and stimulated saliva of MS patients compared to the control group. The serum MBP level had a considerable correlation with its stimulated saliva level. The receiver operating characteristic analysis showed significant diagnostic ability for MBP to discriminate MS patients with serum and stimulated saliva from controls.
\end{abstract}

Conclusion: Serum and saliva level of MBP is lower in MS, so it may be considered a potential biomarker in MS 


\section{Highlights}

- Myelin basic protein in serum and saliva of MS patients is low.

- The serum MBP cut off is $1055 \mathrm{ng} \mathrm{ml} / 1$ with $91 \%$ sensitivity and $100 \%$ specificity.

- The stimulated salivary MBP cut off is $475 \mathrm{ng} \mathrm{ml} / 1$ with $91 \%$ sensitivity and $64 \%$ specificity.

\section{Plain Language Summary}

MS is a debilitating disease that damages the cerebral cortex due to autoimmune disease. To diagnose the disease, MRI (which is an expensive procedure) and biomarkers in cerebrospinal fluid (that is difficult to access and may be problematic for the patient) are used. Saliva can be a good alternative to cerebrospinal fluid. In this study, MBP which is present in the structure of neuronal lining was evaluated in the saliva and serum of patients. The results showed that the amount of MBP increase in both in saliva and serum of patients. It seems that, evaluation of MBP in serum and saliva may be help to detection of MS.

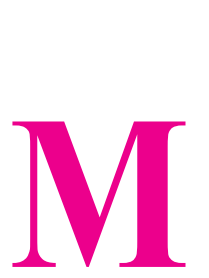

\section{Introduction}

ultiple Sclerosis (MS) is a chronic inflammatory disease of the Central Nervous System (CNS) characterized by myelin loss and decadence of neurons in the brain and spinal cord (Stadelmann, 2011; Ontaneda, Thompson, Fox \& Cohen, 2017). Myelin sheath adjusts nerve impulse conduction rate (Boccaccio \& Steinman, 1996). Myelin Basic Protein (MBP), which is required for the normal function of the vertebrate nervous system (Benjamins \& Morell, 1978), is one of the key elements of the CNS myelin sheath. So, an autoimmune response directed toward MBP may affect the myelin disrupted function in MS (Wucherpfennig, Weiner \& Hafler, 1991).

MS disease starts with motor function deterioration (Polman et al., 2011). For MS diagnosis, clinicians use Magnetic Resonance Imaging (MRI) to show lesions and oligoclonal bands of immunoglobulin $\mathrm{G}$ assaying in Cerebrospinal Fluid (CSF) (Manconi et al., 2018). However, MRI is a time-consuming and costly procedure; $\mathrm{CSF}$ assay requires a lumbar puncture, is very aggressive and painful for the participant, and laborious for the neurologist. So, the CSF assessments are unfeasible to investigate the disease and response to medication. Consequently, new biological markers that can be checked in combination with the present clinical features are essential for a precise and early diagnosis, prognosis prediction, illness management, and determining the effectiveness of an intervention. MBP in CSF has been the focus of most of these efforts (Derkus et al., 2017).
Saliva, as a reflection of oral and systemic healthiness, presents valuable data. Saliva offers a good analytical fluid that can be collected pleasantly, preserved simply, and economically compared to other fluids used in medical laboratories (Agha-Hosseini, Mirzaii-Dizgah \& Mirjalili, 2011). So, we evaluated the MBP level in serum and saliva samples of patients with MS to verify the potential of these markers to diagnose and monitor the disease.

\section{Methods}

The study was approved by the Review Board of the National Institute for Medical Research Development (IR. NIMAD.REC.1397.477), and written informed consent was taken from all participants. Based on McDonald's 2010 criteria with at least 2 clinical attacks (Polman et al., 2011), 32 definitive relapsing-remitting MS women hospitalized in the MS Unit of Imam Reza Hospital, Tehran, Iran in 2018 participated in the study. Furthermore, 29 demographically and ethnically matched healthy females from our university staff were also recruited. Two neurologists assessed Expanded Disability Status Scale (EDSS) in MS patients (Polman et al., 2011).

Venous blood and saliva were taken at the same time from each woman in the morning. Serum and saliva sampling were taken as previously described (MirzaiiDizgah \& Riahi, 2011). The samples were centrifuged at $5000 \mathrm{~g}$ for 10 minutes; the serum and saliva supernatants were kept at $-80^{\circ} \mathrm{C}$ for later measurement of MBP. 
The level of MBP was determined using an ELISA kit (Bioassay Technology Laboratory, Shanghai, China) as stated by the manufacturer's instructions.

The obtained data are presented as a mean \pm SEM. Assessment of between groups means was performed with an unpaired 2-tailed student's $t$ test. The Pearson correlation test was used to confirm the association between the parameters. Receiver Operating Characteristic (ROC) analysis was used to detect the cut-off point for salivary MBP between MS and healthy groups. Analyses were done in SPSS version 16.

\section{Results}

This case-control study assessed 32 MS women as the case group and 29 healthy women as the control. The Mean $\pm \mathrm{SD}$ ages in the case and control group were $35.7 \pm 7.9$ and $36.8 \pm 4.2$ years, respectively.

The mean serum MBP concentration was lower in MS than that of the healthy group (Figure 1A). Stimulated salivary concentrations of MBP were significantly lower in patients with MS (Figure 1B). However, the difference in unstimulated salivary concentrations of MBP between MS and healthy women was not significant (Figure 1C).

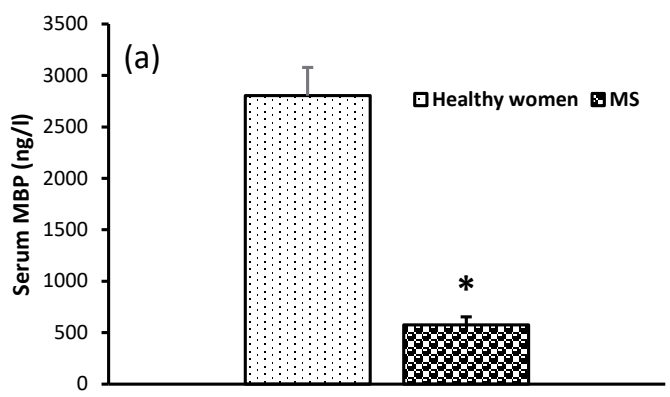

There was a moderate correlation between the stimulated salivary MBP and its serum levels $(\mathrm{r}=0.645$; $\mathrm{P}=0.004$ ). However, there was no significant correlation between serum and unstimulated salivary MBP levels $(\mathrm{r}=0.102 ; \mathrm{P}=0.689)$.

The Mean \pm SD EDSS score was $3.8 \pm 1.7$ in the MS group. EDSS was not significantly correlated with MBP in serum or in stimulated and unstimulated saliva. The mean disease duration in the MS group was 6 years. The serum MBP cut-off value with a sensitivity of $91 \%$, specificity of $100 \%$, and the area under the ROC curve of 0.977 was $1055 \mathrm{ng} / \mathrm{L}$.

The cut-off value of stimulated salivary MBP for the diagnosis of MS was $475 \mathrm{ng} / \mathrm{L}$ (ROC-area under the curve $=0.833$ ). With this cut-off point, the sensitivity was $75 \%$, and specificity was $64 \%$.

\section{Discussion}

MS is a chronic, immunologically intermediated disease of the CNS, characterized by inflammation and myelin loss of white matter in the brain and spinal cord. The main complaint of young people, especially females with MS, is the decline in the quality of their life. MBP is one of the key elements of the myelin sheath and the primary target for the autoimmune response (Harauz et al., 2004),

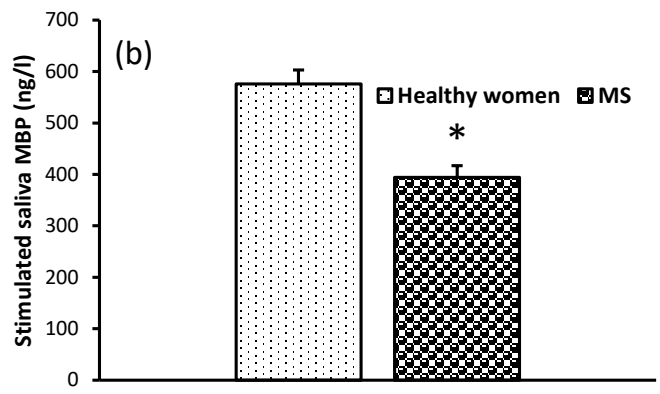

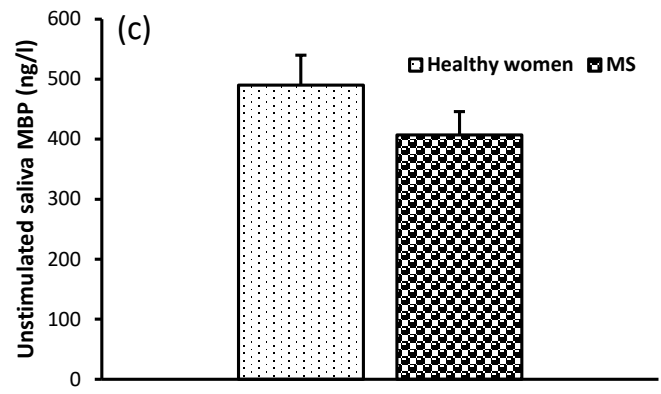

Figure 1. Serum and saliva concentration of Myelin Basic Protein (MBP)

Means $\pm S E M$ in women with Multiple Sclerosis (MS); ${ }^{*}<<0.05$. 
so determining its quantity in serum and saliva can support the diagnosis and management of the disease. This study aimed to evaluate the salivary and serum values of MBP in MS women. The present study has shown that serum and stimulated salivary levels of MBP are low in women with MS than healthy people. Additionally, the stimulated salivary levels of MBP correlate well with its serum concentration. In addition, the receiver operating characteristic analysis showed significantly diagnostic abilities for MBP to discriminate MS patients with serum and stimulated saliva from the controls. To the best of our knowledge, this is the first finding on the decrease of saliva and serum MBP concentrations in MS.

MBP is the second abundant copious protein of the myelin sheath in the CNS. As a result of its essential function in CNS myelin production and completion, MBP has been regarded as a functional molecule of myelin. MBP is very basic and delivers an extremely positive charge. As an unstructured protein, MBP has appropriate flexibility; thus, it can interact with negatively charged lipids and other polyanionic proteins (Zhang et al., 2014). Autoantibodies to MBP were described in CSF of MS patients in many studies (Panitch, Hooper \& Johnson, 1980; Warren \& Catz, 1986; Catz \& Warren, 1986; Warren \& Catz, 1999; Terryberry, Thor \& Peter, 1998; Reindl et al., 1999; Chamczuk, Ursell, O’Connor, Jackowski \& Moscarello, 2002). As autoantibodies to MBP were bound to other proteins in CSF, it is challenging to detect autoantibodies against MBP in MS (Warren \& Catz, 1986).

The MS diagnosis criteria are as follows: 1) suffering from numbness, tingling, weakness, vision loss, walking loss, incoordination, imbalance, and bladder dysfunction; 2) lesion in MRI findings in white matter; 3) extended central motor transmission times; and 4) increasing immunoglobulin concentrations and the presence of two or more oligoclonal bands in CSF (Polman et al., 2011; Hunter, 2016). Because MRI is expensive and CSF exam is an invasive procedure, evaluating biomarkers in the serum and saliva as an alternative procedure is of value.

Several studies have suggested applying salivary evaluations for diagnosing, managing, or predicting the prognosis of illnesses. In this regard, numerous biological molecules can be assayed in the saliva of diseased individuals, for instance, cortisol (Agha-Hosseini et al., 2011; Agha-Hosseini, Mirzaii-Dizgah \& Mirjalili, 2012) and testosterone (Agha-Hosseini, Moosavi \& MirzaiiDizgah, 2013) in xerostomia, troponin (Mirzaii-Dizgah \& Riahi, 2013) and cathepsin L (Mirzaii-Dizgah \& Riahi, 2011) in myocardial infarction, epidermal growth factor (Agha-Hosseini, Mohebbian, Sarookani, Harirchi \&
Mirzaii-Dizgah, 2015) and muscarinic cholinergic receptors (Agha-Hosseini, Mirzaii-Dizgah \& Mohammadpour, 2016) in lichen planus, and glucose (Mirzaii-Dizgah, Mirzaii-Dizgah \& Mirzaii-Dizgah, 2016) in diabetes mellitus. Saliva is holding promises as a research fluid in future investigations. It has received considerable interest as a biological sample because of its fast, simple, and nonaggressive collection. To substitute saliva for plasma or CSF for biological assessments, there must be a high association between plasma and saliva regarding the evaluated biomarkers. As our study showed, there was a moderate association between serum MBP and stimulated saliva MBP. We can assume that saliva-based assays may be used to detect MS by determining salivary MBP.

It was shown that autoantibodies from the serum of different autoimmune diseases could possess enzymatic activities (Bezuglova, Konenkova, Buneva \& Nevinsky, 2012). MBP-hydrolyzing activity is an essential property of IgGs, IgMs, and IgAs from sera and CSF of MS patients (Doronin et al., 2014). Therefore, the hydrolyses of MBP by autoantibody produced in these patients may be the mechanism of the low level of MBP in MS patients compared with healthy individuals.

There were some limitations to the present study. For example, we did not assay MBP in CSF due to ethical considerations, especially in the control group. So, we did not analyze the correlation of MBP content between serum, saliva, and CSF. Moreover, all study patients had relapsing-remitting $\mathrm{MS}$, and we did not include patients with other types of MS.

\section{Conclusions}

Serum and saliva level of MBP is lower in MS, and it may be considered a potential biomarker in diagnosing MS.

\section{Ethical Considerations}

\section{Compliance with ethical guidelines}

The study was approved by the Review Board of the National Institute for Medical Research Development (No.: IR.NIMAD.REC.1397.477).

\section{Funding}

This study was supported by grants from the National Institute for Medical Research Development (NIMAD), Deputy of Research and Technology, and Ministry of Health and Medical Education of Iran (Grant No.: 958690). 


\section{Authors' contributions}

Methodology, writing the original draft, review and editing, resources: All authors; Supervision: Iraj MirzaiiDizgah.

\section{Conflict of interest}

The authors declared no conflict of interest.

\section{Acknowledgments}

The authors want to thank the National Institute for Medical Research Development (NIMAD), Deputy of Research and Technology, and Ministry of Health and Medical Education of Iran.

\section{References}

Agha-Hosseini, F., Mirzaii-Dizgah, I., \& Mirjalili, N. (2012). Relationship of stimulated whole saliva cortisol level with the severity of a feeling of dry mouth in menopausal women. Gerodontology, 29(1), 43-7. [DOI:10.1111/j.1741-2358.2010.00403.x] [PMID]

Agha-Hosseini, F., Mirzaii-Dizgah, I., \& Mirjalili, N. (2011). Relationship of unstimulated saliva cortisol level with severity of oral dryness feeling in menopausal women. Australian Dental Journal, 56(2), 171-4. [DOI:10.1111/j.1834-7819.2011.01320.x] [PMID]

Agha-Hosseini, F., Mirzaii-Dizgah, I., \& Mohammadpour, N (2016). Muscarinic cholinergic receptors (MR3) in saliva of patients with oral lichen planus. Archives of Dermatological Research, 308(7), 481-6. [DOI:10.1007/s00403-016-1670-7] [PMID]

Agha-Hosseini, F., Mohebbian, M., Sarookani, M. R., Harirchi, I., \& Mirzaii-Dizgah, I. (2015). Comparative evaluation of EGF in oral lichen planus and oral squamous cell carcinoma. Acta Medica Iranica, 53(8), 471-5. [PMID]

Agha-Hosseini, F., Moosavi, M. S., \& Mirzaii-Dizgah, I. (2013) Salivary flow, testosterone, and femur bone mineral density in menopausal women with oral dryness feeling. Oral Surgery, Oral Medicine, Oral Pathology and Oral Radiology, 115(5), 612-6. [DOI:10.1016/j.oooo.2012.11.014] [PMID]

Benjamins, J. A., \& Morell, P. (1978). Proteins of myelin and their metabolism. Neurochemical Research, 3(2), 137-74. [DOI:10.1007/BF00964057] [PMID]

Bezuglova, A. M., Konenkova, L. P., Buneva, V. N., \& Nevinsky, G. A. (2012). IgGs containing light chains of the $\lambda$ - and K- type and of all subclasses (IgG1-IgG4) from the sera of patients with systemic lupus erythematosus hydrolyze myelin basic protein. International Immunology, 24(12), 759-70. [DOI:10.1093/intimm/dxs071] [PMID]

Boccaccio, G. L., \& Steinman, L. (1996). Multiple sclerosis: From a myelin point of view. Journal of Neuroscience Research, 45(6), 64754. [DOI:10.1002/(SICI)1097-4547(19960915)45:6<647::AIDJNR1>3.0.CO;2-8]
Catz, I., \& Warren, K. G. (1986). Intrathecal synthesis of autoantibodies to myelin basic protein in multiplesclerosis. Canadian Journal of Neurological Sciences, 13(1), 21-4. [DOI:10.1017/ S0317167100035745] [PMID]

Chamczuk, A. J., Ursell, M., O'Connor, P., Jackowski, G., \& Moscarello, M. A. (2002). A rapid ELISA-based serum assay for myelin basic protein in multiple sclerosis. Journal of Immunological Methods, 262(1-2), 21-7. [DOI:10.1016/S00221759(01)00522-1]

Derkus, B., Acar Bozkurt, P., Tulu, M., Emregul, K. C., Yucesan, C., \& Emregul, E. (2017). Simultaneous quantification of Myelin Basic Protein and Tau proteins in cerebrospinal fluid and serum of Multiple Sclerosis patients using nanoimmunosensor. Biosensors and Bioelectronics, 89(Pt 2), 781-8. [DOI:10.1016/j.bios.2016.10.019] [PMID]

Doronin, V. B., Parkhomenko, T. A., Castellazzi, M., Padroni, M., Pastore, M., \& Buneva, V. N., et al. (2014). Comparison of antibodies hydrolyzing myelin basic protein from the cerebrospinal fluid and serum of patients with multiple sclerosis. PLoS One, 9(9), e107807. [DOI:10.1371/journal.pone.0107807] [PMID] [PMCID]

Harauz, G., Ishiyama, N., Hill, C. M. D., Bates, I. R., Libich, D. S., \& Farès, Ch. (2004). Myelin basic protein-diverse conformational states of an intrinsically unstructured protein and its roles in myelin assembly and multiple sclerosis. Micron, 35(7) 503-42. [DOI:10.1016/j.micron.2004.04.005] [PMID]

Hunter, S. F. (2016). Overview and diagnosis of multiple sclerosis. American Journal of Managed Care, 22(6 Suppl), S141-50. https://www.ajmc.com/view/cost-effectiveness-multiplesclerosis-overview-diagnosis

Manconi, B., Liori, B., Cabras, T., Vincenzoni, F., Iavarone, F., \& Lorefice, L., et al. (2018). Top-down proteomic profiling of human saliva in multiple sclerosis patients. Journal of Proteomics, 187, 212-22. [DOI:10.1016/j.jprot.2018.07.019] [PMID]

Mirzaii-Dizgah, I., \& Riahi, E. (2013). Salivary high-sensitivity cardiac troponin $\mathrm{T}$ levels in patients with acute myocardia infarction. Oral Diseases, 19(2), 180-4. [DOI:10.1111/j.16010825.2012.01968.x] [PMID]

Mirzaii-Dizgah, I., \& Riahi, E. (2011). Serum and saliva levels of cathepsin L in patients with acute coronary syndrome. The Journal of Contemporary Dental Practice, 12(2), 114-9. [DOI:10.5005/jp-journals-10024-1019] [PMID]

Mirzaii-Dizgah, M. H., Mirzaii-Dizgah, I., \& Mirzaii-Dizgah, M. R. (2016). Oral glucose tolerance test in unstimulated saliva of healthy individuals. European Journal of General Dentistry, 5(1) 15-8. http://eprints.iums.ac.ir/4187/

Ontaneda, D., Thompson, A. J., Fox, R. J., \& Cohen, J. A. (2017). Progressive multiple sclerosis: Prospects for disease therapy repair, and restoration of function. The Lancet, 389(10076) 1357-66. [DOI:10.1016/S0140-6736(16)31320-4] [PMID]

Panitch, H. S., Hooper, C. J., \& Johnson, K. P. (1980). CSF antibody to myelin basic protein. Measurement in patients with multiple sclerosis and subacute sclerosing panencephalitis. Archives of Neurology, 37(4), 206-9. [DOI:10.1001/archneur.1980.00500530044005] [PMID]

Polman, C. H., Reingold, S. C., Banwell, B., Clanet, M, Cohen, J. A., \& Filippi, M., et al. (2011). Diagnostic criteria for multiple sclerosis: 2010 revisions to the McDonald criteria. Annals of 
Neurology, 69(2), 292-302. [DOI:10.1002/ana.22366] [PMID] [PMCID]

Reindl, M., Linington, Ch., Brehm, U., Egg, R., Dilitz, E., \& Deisenhammer, F., et al. (1999). Antibodies against the myelin oligodendrocyte glycoprotein and the myelin basic protein in multiple sclerosis and other neurological diseases: A comparative study. Brain, 122(11), 2047-56. [DOI:10.1093/ brain/122.11.2047] [PMID]

Stadelmann, Ch. (2011). Multiple sclerosis as a neurodegenerative disease: Pathology, mechanisms and therapeuticimplications. Current Opinion in Neurology, 24(3), 224-9. [DOI:10.1097/ WCO.0b013e328346056f] [PMID]

Terryberry, J. W., Thor, G., \& Peter, J. B. (1998). Autoantibodies in neurodegenerative diseases: Antigen-specific frequencies and intrathecal analysis. Neurobiology of Aging, 19(3), 205-16. [DOI:10.1016/S0197-4580(98)00049-9]

Warren, K. G., \& Catz, I. (1999). An extensive search for autoantibodies to myelin basic protein in cerebrospinal fluid of nonmultiple-sclerosis patients: Implications for the pathogenesis of multiple sclerosis. European Neurology, 42(2), 95-104. [DOI:10.1159/000069418] [PMID]

Warren, K. G., \& Catz, I. (1986). Diagnostic value of cerebrospinal fluid anti-myelin basic protein in patients with multiple sclerosis. Annals of Neurology, 20(1), 20-5. [DOI:10.1002/ ana.410200105] [PMID]

Wucherpfennig, K. W., Weiner, H. L., \& Hafler, D. A. (1991) T-cell recognition of myelin basic protein. Immunology Today, 12(8), 277-9, 281-2. [DOI:10.1016/0167-5699(91)90126-E]

Zhang, J., Sun, X., Zheng, S., Liu, X., Jin, J., \& Ren, Y., et al. (2014). Myelin basic protein induces neuron-specific toxicity by directly damaging the neuronal plasma membrane. PLoS One, 9(9), e108646. [DOI:10.1371/journal.pone.0108646] [PMID] [PMCID] 